\title{
A Study on the Possibility of Preserving Selected Vegetable Blends by Fermentation
}

\section{By}

Ruvini Udayangani Pathirana.

Thesis submitted to the University of Sri Jayewardenepura as the partial fulfillment requirement

for the award of degree of

Master of Science

In

Food Science \& Technology. 
We certify that the above statement made by the candidate is true and this thesis is suitable for submission to the university for the purpose of evaluation.

\section{Supervisors:}

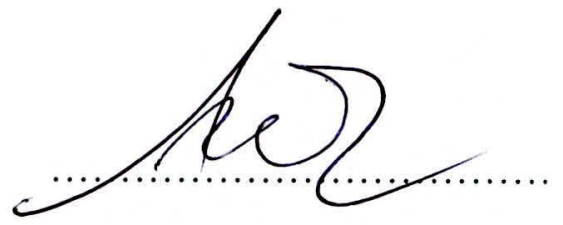

Professor A. Bamunuarrachchi

Professor of Food Science

Department of Food Science \&

Technology,

University of Sri Jayawardenapura,

Nugegoda.

$31^{\text {st }}$ August 2008.

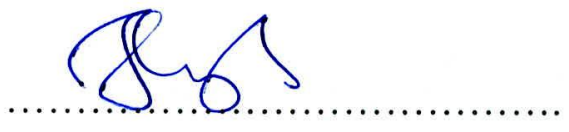

Dr. (Mrs) T. K. Weerasinghe

Senior Lecturer

Department of Botany,

The Open University of Sri Lanka,

Nugegoda. 


\section{CONTENT}

Page no:

LIST OF TABLES iv

LIST OF FIGURES v

LIST OF PLATES v v

ACKNOWLEDGEMENT vi

ABSTRACT vii

1.0 INTRODUCTION 1

1.1 General Introduction 1

1.2 Objectives 4

2.0 LITERATURE REVIEW $\mathbf{6}$

2.1 Fermentation - As a Method of Food Preservation 6

2.2 Fermentation of Vegetables 8

2.2.1 Potential for Vegetable Fermentation 8

2.2.2 Fermented Vegetable Products 9

2.2.3 Methods of Vegetable Fermentation 13

2.2.3.1 Salting 13

2.2.3.2 Fermenting 14

2.2.3.3 Pickling 16

2.2.4 Manufacture of Lactic Acid Fermented Vegetables $\quad 17$

2.3 Lactic Acid Fermentation 21

2.3.1 Lactic Acid Bacteria 21

2.3.2 Chemistry of Lactic Acid Fermentation 27

2.3.3 Microbiology of Lactic Acid Fermented Vegetables 30

2.4 Measures Ensuring Proper Fermentation of Vegetables 35

2.4.1 Conditions of the Fermenting Mass 35

2.4.2 Supplementary Measures . 36

2.5 Problems Encountered in Vegetable Fermentation 38

2.6 Advances of Vegetable Fermentation 41

2.6.1 Use of Starter Cultures 41

2.6.2 Developments in Lactic Acid Fermentation 42 
3.0 METHODOLOGY

3.1 Selection of Vegetables 46

3.2 Fermentation of Selected Vegetables Alone 46

3.3 Fermentation of Kakiri and Capsicum in Blends 47

3.4 Fermentation of Selected Vegetables in Blends 48

3.5 Bottling of Fermented Vegetables 49

3.6 Chemical Analysis of Fermented Vegetable Products 50

3.6.1 Detection of $\mathrm{pH} \quad 50$

3.6.2 Measurement of Acidity as Lactic Acid Acidity 51

3.7 Microbiological Analysis During Fermentation of Mixed Vegetables $\quad 52$

3.7.1 Isolation of Microorganisms 52

3.7.2 Screening of Microorganisms 53

3.7.3 Identification of Bacteria 53

3.7.3.1 Morphological Characterization of Bacteria 53

3.7.3.2 Biochemical Characterization of Bacteria 54

3.7.4 Identification of Fungi \& Yeasts 59

3.8 Microbiological Quality of Final Product 59

3.8.1 Culturing of Final Products $\quad 59$

$\begin{array}{ll}\text { 3.8.2 Enumeration of Microorganisms } & 60\end{array}$

$\begin{array}{lll}3.9 & \text { Sensory Evaluation } & 60\end{array}$

4.0 RESULTS \& DISCUSSION

4.1 Variation in $\mathrm{pH}$ and Acidity (Lactic Acid) 63

4.2 Microbiological Quality of Fermented Products 70

4.3 Microbiological Safety of the Final Product 77

4.4 Sensory Evaluation of the Final Product 77 


\section{REFERENCES}

\section{APPENDIX}

Appendix A - Microbiological Culture Media

Appendix B - Reagents

Appendix C - Questionnaire for Sensory Analysis 


\section{LIST OF TABLES}

Table No 2.1: Some Common Acid-fermented Vegetables Produced in Different Regions of The World

Table No 2.2: Taxonomic Subdivisions of Lactic Acid Bacteria

Table No 2.3: Optimum Temperatures for Growth of Some Groups of Microorganisms Important for Lactic Acid Fermentation

Table No 4.1: Variation of Average $\mathrm{pH}$ during Fermentation with Time

Table No 4.2: Variation of Acidity (as Lactic Acid) during Fermentation with Time

Table No 4.2: Variation of Acidity (as Lactic Acid) during Fermentation with Time

Table No 4.3: The Total Plate Count, Yeast \& Mold Count and Coliform Count of the Fermented Products

Table No 4.4: $\quad$ Morphological Characters of Isolated Bacteria

Table No 4.5: Preliminary Identification of Isolated Bacteria

Table No 4.6: Morphological Characters of !solated Fungal Species and Their Identification

Table No 4.7: Identification of Yeast Isolates based on Morphological Characteristics

Table No 4.8: Attribute Diagnostic Scores of Hedonic Test

Table No 4.9: Attribute Diagnostic Scores for Flavor \& Texture Profile 


\section{LIST OF FIGURES}

Figure 2.1: Flow Chart of the Production of Fermented Vegetables $\left({ }^{*}\right.$ depending on the species of vegetable and the method used)

Figure 4.1: Variation of $\mathrm{pH}$ with Fermentation time in Different Vegetavie ı ypes

Figure 4.2: Variation of Lactic Acid Acidity with Fermentation time in Different Vegetable Types

\section{LIST OF PLATES}

PLATE 01: Fermentation of Vegetables in Laboratory Scale Fermenting Vessels

PLATE 02: Fermented Mixed Vegetable Product 


\section{ACKNOWLEDGEMENT}

I wish to express my sincere gratitude to my supervisors, Professor A.Bamunuarachchi, Department of Food Science \& Technology, University of Sri Jayawardanepura, Sri Lanka and Dr. (Mrs.) T.K. Weerasinghe, Head, Department of Botany, The Open University of Sri Lanka, for giving me their support and guidance with patience throughout my research project to make it a successful.

My sincere thanks also extend towards Dr.K.K.D.S. Ranaweera (Head, Department of Food Science \& Technology, USIP), and rest of the academic staff whose encouraging comments given throughout made my work a success.

It is with great attitude I acknowledge the invaluable support given to me during the laboratory work, by the technical staff of the Department of Botany, OUSL to overcome many practical difficulties. The kind assistance given to me by the nonacademic staff of the Department of Food Science \& Technology, USJP should also acknowledge.

I am indebtly thankful to my dear friends, Sandamini and Dilesha for their generous support given to me during my heavy workload.

Finally my gratitude goes to my loving Amma, Thaththa and nangi from whom I received extensive moral support. 


\begin{abstract}
Fermented foods are of great significant because the process provides not only a preservative technology but also make nutritious foods with a wide variety of flavours, aromas and textures and being a good alternative in salvaging food wastes. Though fermented vegetable products are not much popular in Sri Lanka, the potential for such a food industry is invaluable as there is a considerable post harvest loss of agriculture produce in Sri Lanka. The technology also can be used to overcome the food crisis that will be faced in the near future by the whole world. This research was carried out with the overall objective of identifying the potential for mixed vegetable fermentation and the products' consumer acceptability.
\end{abstract}

Common Sri Lankan low country grown vegetables, namely kakiri (Cucumis melo), capsicum (Capsicum annuum), winged bean / dambala (Phaseolus lunatus), long bean / snake bean / mekaral (Vigna unguiculata subsp. sesquipedalis) and up country grown carrot (Daucus carota) were fermented alone and in blends using $6 \%$ salt solution and the lactic acid fermentation was monitored through reduction in $\mathrm{pH}$ and development of lactic acid acidity. All the products were analyzed for microbiological quality using standard microbiological techniques. The fermenting medium of mixed vegetables was analyzed microbiological quality in order to identify the responsible microbial community in fermentation. A sensory analysis was carried out through a questionnaire using untrained panelists. Both from the hedonic test and flavour and texture profile analysis, the consumer acceptability was measured. 
In vegetable fermentation alone, the rate of $\mathrm{pH}$ reduction was higher during the first three days while the rate was slower at the latter part of fermentation. As an average the $\mathrm{pH}$ gradually decrease from 7.0 to 3.4 at the end of the fermentation period of 12 days. This resulted in development of lactic acid acidity up to an average value of $0.32 \%$

For mixed vegetable fermentation, the maximum acidity reached a constant level by the end of ten day period, fermentation can be carried out within a ten day period during which the maximum lactic acid acidity would be attained. A packaging solution containing $1.5 \%$ salt and $1.5 \%$ vinegar was found to be a satisfactory medium for the final product to be packed.

The microbiological analysis of fermenting medium of mixed acid fermentation revealed that typical lactic acid bacteria which included Lactobacillus plantarum as the frequent isolates, while L. brevis, Leuconostoc and Pediococcus were also found among the fermenting microbial community. During fermentation, the medium is highly susceptible to spoilage by Aspergillus and Penicillium species. This was obviously related to the environmental hygiene as well as to raw material quality.

The final product of vegetables derived in the study was microbiologically safe for consumption as there was no detection of spoilage bacteria, fungi and coliforms.

According to the sensory analysis, the fermented mixed vegetable product is acceptable to the consumers. 


\subsection{INTRODUCTION}

\subsection{GENERAL INTRODUCTION}

Fermentation has been practising since a long time to slow down the rottenness of milk, vegetables, meats and many other food types thereby prolong the shelf life of food for several months. Indigenous fermented foods such as bread, cheese, wine and sauerkraut have been prepared and consumed in rural households and villages for thousands of years and are strongly linked with culture and tradition (FAO, 1998).

Apart from extending the shelf life, fermentation has also being a remedy for seasonal overproduction of many crops thus salvaging food wastes. This also creates unique flavours, brings changes in textural properties and improves digestibility of foods so it enhances consumer palatability.

Indigenous fermented fruits and vegetables play an important role in food preservation and more over they has a high potential to contribute to the growing food needs of the world (FAO, 1998).

However, the increasing popularity of fermentation technology is due to its low investment, simple machinery and low technology involvement with compared to other preservative methods.

Therefore, fermentation of vegetables has been widely studied over the past century and many of researches are focus mainly on improving the understanding of fermented products (i.e. its chemistry and microbiology), refining the process and new product development. 
Fermentation of perishable vegetables is solely based on lactic acid fermentation carried out by lactic acid bacteria. These bacteria produce organic acids mainly lactic acid and acetic acid which serve as effective antimicrobial agents which reduces the $\mathrm{pH}$ in the food thus preventing the growth of most food spoiling microorganisms (Lee, 1997).

The classic fermented vegetable products are sauerkraut in which shredded cabbages are salted and Korean Kimchi, that made from fermentation of Korean cabbage and radish with minor ingredients including garlic, red pepper, green onion, ginger and salt. Up to now so many types of vegetables such as cucumber, radishes, carrots, mustard leaves, onion and capsicum are acid fermented in the presence of salt around the world (FAO, 1998).

As agriculture plays a significant role in Sri Lankan economy, vegetable farming and processing should be developed in order to achieve the maximum profit.

During 1993, annual per capita vegetable availability stands at about $42 \mathrm{~kg}$, about half of the recommended level. However, strong seasonal variation in vegetable supply, indicated by seasonal price swings suggests that the problem of low availability more serious in some months than in others (AVRDC, 2000) thus paving the way to import market. The post harvest losses of vegetables are a predominant failure in the current market as well as at the field and thus implementation of food preservative techniques at the domestic level is a must.

Preservation of surplus vegetables by lactic acid fermentation could be readily carry out at domestic level even at the farm itself and thus it will improve the supply and 
availability of vegetable foods throughout the year and also the nutrition of the population.

This technology has a great potential to improve among poor and underdeveloped regions of the world by simply teaching the people giving them the knowledge to maximise the benefit of the technology and to improve the hygienic conditions of the food

Lactic acid fermented foods generally require little, if any, heat in their fermentation and can be consumed without cooking, for examples, pickled vegetables, sauerkraut, and kimchi. Indonesian tempe fermentation converts soybeans that would require as much as 5-6 hours cooking to a product that can be cooked in soup with 5-10 min boiling (Steinkraus, 1997). So that fermented food will be a good indirect alternative to reduce fuel requirement as fuel is becoming a scarce and economically unaffordable resource especially in developing countries.

Fermented vegetables are not very popular in Sri Lanka and there is no other way than drying has been practising to preserve vegetables. Since fermented food resembles more closely to the fresh product than dried product and as fermentation impart a characteristically enhanced flavour to the final product, consumer acceptability could be enhanced by introducing this technology to the country. Thus some studies related to vegetable fermentation has already done here in Sri Lanka and they revealed the possibility of fermenting cucumber (Cucumis sativus), kekiri (Cucumis melo), Capsicum (Capsicum annum) and karawila (Momordica charantia) in the presence of salt (Ranasinghe,1993; Singhakumara,1994; Mahinda, 2003; Rathnayake,2005;). 
In 1997, Sudasinghe showed the potential for semi-commercial scale manufacturing and marketing of fermented Capsicum in Sri Lanka thus it gave the first hope of succeeding the fermented vegetable industry within the country. Currently, fermented gherkins are being produced for export market while some of imported fermented vegetable products such as gherkin, baby corn are available in the Sri Lankan market. Therefore, encouraging vegetable fermentation as a method of preservation and development of such commercial products would help to save much foreign exchange as well as fill out the deficiency in contributing to international vegetable trade.

This study is an attempt to find out the possibility of fermenting some of common and perishable low country vegetables available throughout the year, to be used as a side dish or to be used after further preparation. The method could be practised at domestic level and if introduced to the local as well as export market would be profitable venture if the fermented product is successfully developed.

\subsection{OBJECTIVES}

Fermentation technology has confronted new challenges in the era of functional food with its efficient biosynthesis potential. Research for selection of useful strains from traditional fermented foods and new product development are continuing worldwide and relevant information is accumulating.

Mixed vegetables fermentation would lead to a new look for preserved vegetables. Since low country vegetables are abundant through out Sri Lanka and due to relative low prices, derived fermented product may be worth while. 
Therefore this research was carried out to reach following achievements with product development.

\section{Specific Objectives}

- To identify the suitable conditions (salt concentration, time duration and packaging) for brine salted fermentation of five selected vegetables alone and in blends.

- To characterize the microbial flora involved in mixed vegetable fermentation process.

- To evaluate the microbial quality of the final product.

- To carry out a sensory evaluation for the final mixed vegetable product.

\section{Overall Objective}

- To develop a fermented product from vegetables in blends and to investigate its sensory qualities. 